Int Journal Of Health Manag. And Tourism 2018, 3(1), 23-41

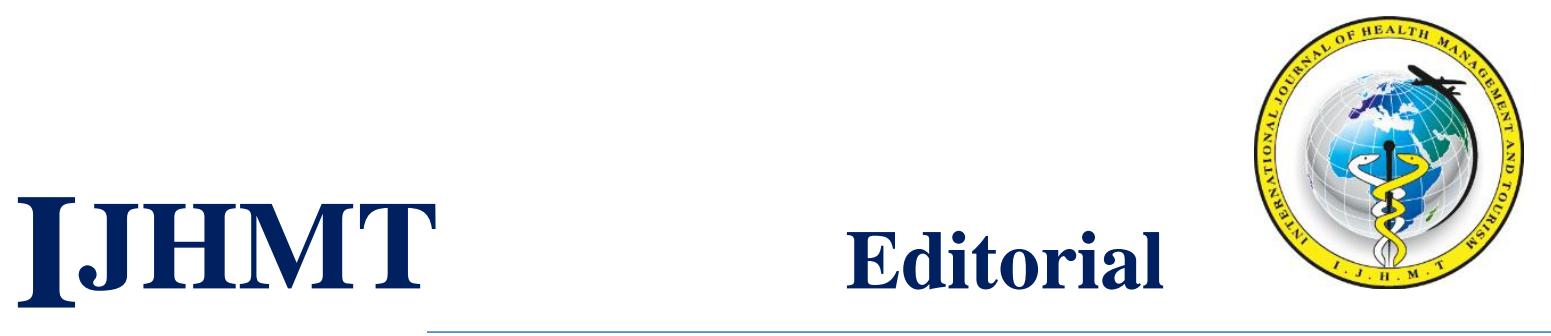

Internatıonal Journal Of Health Management And Tourism

\title{
DEVISING A BUSINESS MODEL FOR THE LABORATORY FOR WELLNESS AND MOTOR BEHAVIOR TO PROMOTE INDEPENDENT LIVING OPPORTUNITIES FOR STROKE SURVIVORS
}

\author{
Chris Shao', Ceyhan Kilic ${ }^{2}$, Turkan Dursun ${ }^{3 *}$ \\ ${ }^{1}$ Ph.D. Prof. of Marketing, College of Business Administration, Tarleton State University, USA \\ ${ }^{2}$ Ph.D. Assist Prof of Marketing, College of Business Administration, Tarleton State University, USA \\ ${ }^{3}$ Ph.D. Assoc. Prof of Marketing, Paul and Virginia Engler College of Business, West Texas A\&M University, USA \\ "E-mail: tkilic@wtamu.edu
}

\begin{abstract}
This is a case-based conceptual study that focuses on the business model of the Laboratory for Wellness and Motor Behavior (LWMB) which is not-for-profit and housed at a state university in Texas, the United States of America. The LWMB was established by a kinesiology professor who started working with kinesiology students whose focus is in allied health to provide services to individuals who have spinal cord injuries or other neurological disabilities. Using a team approach, the LWMB, under the kinesiology professor's supervision, works closely with the patrons and their families, and the graduate assistants and interns from the Kinesiology Department of the university. Even though relatively unknown to the general public, the Laboratory has been successful in helping the patrons and training the students. Nevertheless, in order to remain sustainable and to continuously "provide access to the benefits of exercise to those who otherwise are disregarded" (Priest, 2016), a comprehensive business model is needed to help the LWMB warrant its "success and future expansion". The purpose of this paper is to analyze the current business model of the LWMB and then provide recommendations to improve it. A theoretical framework that shows potential outcomes of the improved business model for the stroke survivors and interns is also presented. The results of the market analysis show that this laboratory operates in a very competitive and technologically turbulent business environment with many opportunities and threats. Several recommendations are made for LWMB to improve its business model to deal with the challenges of its internal and external operating environments.
\end{abstract}

Keywords: Business model, marketing strategy, people with disabilities, stroke survivors, wellness, motor behavior, laboratory, total well-being, total movement, independent living 


\section{Introduction}

After years of researching and publications on the rehabilitation of stroke survivors and working directly with the stroke survivors, a kinesiology professor working at a state university in Texas, the United States of America, has concluded that there are still hopes for these survivors to recover physically, to a certain degree, and psychologically as well as emotionally, to a large degree, from a stroke. Based on this belief, he established the Laboratory for Wellness and Motor Behavior (LWMB) and started working with Kinesiology "students whose focus is in allied health" to provide services to individuals "who have spinal cord injuries or other neurological disabilities" (LWMB, 2016).

The Laboratory for Wellness and Motor Behavior (LWMB) is a lab that aims to help specifically for stroke survivors. In general, the LWMB provides "access to the benefits of exercise to those who otherwise are disregarded" (Priest, 2016). Specifically, it targets people "who have been released from conventional healthcare and usually have had a stroke or injury that has left them paralyzed" (LWMB, 2016). And, a majority of patrons are from the region, though one of them was from as far as the state of Hawaii (Priest, 2017). As far as strategic positioning is concerned, the LWMB would like to be perceived by public as a training center that provides "total well-being" and "total movement needs for independent living" by attending to patrons "with dignity and respect" and with a team approach (Priest, 2016).

\section{Lwmb's Marketing Mix Strategy}

\section{Product/Service Component}

The LWMB's product (i.e., a service) consists of both intangible components such as the interactions between the interns and patrons, and tangible components such as the facility and the equipment. Supported by both of these components, the LWMB offers opportunities for total "well-being" and "movement needs for independent living" as the core service, while backed by several supplementary services (Wirtz, Chew and Lovelock, 2012). Both the core and supplementary services deliver benefits such as dignity and respect to patrons, personalized/customized workouts, and a warm and friendly environment for socialization.

From the perspective of service mix, the LWMB offers only one service line, the Psycle that allows patrons to "incorporate the same principles of wellness and physical exercise that are recommended for the non-injured population" (LWMB, 2016). The line is people-processing in nature and involves directing intangible service toward people as service recipients (Wirtz, Chew and Lovelock, 2012). 


\section{Price Component}

Since the LWMB's service is free for patrons, the financial sacrifice needed to receive the service does not exist, except for the expenses of traveling to the Laboratory. Nevertheless, there is a sacrifice of time and effort devoted to becoming well. The free service is based on the philosophy that patrons should not have to pay to become well once everyone else has given up on them due to medical and/or financial reasons (Priest, 2017).

\section{Place Component}

The LWMB is housed in the Kinesiology Building of the university. The Laboratory's operation hours are Monday through Thursday, 8:00 a.m.-12:00 p.m. and 1:00 p.m.-3:00 p.m. On Fridays, it is open from 8:00 a.m. to 12:00 p.m. Due to the equipment needed and the interns involved, the patrons have to go to the Laboratory physically to receive the services offered during the operation hours (i.e., facility-dependent services).

\section{Promotion Component}

The main marketing communications tool utilized by the LWMB is word-of-mouth (WOM) communication. The Laboratory also has a page on the University's website and a simplistic pamphlet. Though on a limited basis (i.e., fewer than 100 followers), social media are used (i.e., Twitter) to function as a source of WOM communication. In the Spring 2016 issue of the University's magazine, the LWMB was featured as the cover story.

\section{Service Procedure}

Process, or service experience, is "the actual procedure, mechanisms, and flow of activities" by which the continuing education is delivered and through which the students must go (Zeithaml, Bitner and Gremler, 2013). In general, the process starts when prospective patrons inquire about the LWMB; this can be done online, by phone, by mail, or in person. Then, they begin the process by bringing to the Laboratory a signed consent from their physicians. After that, graduate assistants set up schedules based on the patrons' preferences and conditions. Once their schedules are set, the patrons start to work with interns during the scheduled time period in the Kinesiology Building of the university.

The length of the time period and the number of times to work with the Laboratory are totally depending upon the patron's self-will. Additionally, patrons make his/her own decisions to terminate the visit to the Laboratory.

\section{Service Personnel}

There are two types of personnel involved in the delivery of the LWMB's service. The frontstage personnel include typically kinesiology students working as interns. Before they can 
work in the Laboratory, the interns are required to obtain theoretical background as well as hands-on training from their course work. These interns are senior students who use the opportunity to work in the Laboratory to fulfill their degree requirements; three hundred hours are required to complete their internships. Currently, there are 14 interns working with about 45 to 50 patrons. The back-stage personnel consist of 2 graduate assistants (GAs) who function as administrative assistants and the kinesiology professor, who manages the Laboratory.

\section{External Environment Of Lwmb}

\section{Competitive Factors}

When the LWMB is considered to be a part of an industry consisting of not-for-profit organizations that are open to the general public for total wellness in the North and Central Texas region, the Laboratory does not have any industry competitor. As far as substitutes (i.e., indirect competitors) are concerned, there are four categories of them: Government programs (e.g., Paralyzed Veterans of America) offering both physical and psychological rehabilitation is the first category. Even though they are not-for-profits organizations offering wellness as the major benefit, they are open only to specific groups of individuals (e.g., veterans) and are not in the target region. The second category consists of corporate gyms (e.g., 24-Hour Fitness) that offer a facility for individuals to primarily get "fit" physically. The third category includes medical therapies (e.g., physical therapists) that are for-profit in nature. Finally, home programs/workout activities (e.g., P90X) offering a portable, and convenient means for individuals to become well is the last category.

Buyers of the industry (i.e., patrons) can be described as those who need/want to use the benefits provided by the industry to get well. The current buyers are mainly from the North and Central Texas. Suppliers, who can adversely affect the LWMB's operations, include manufacturers of major equipment, interns who are available to work with the patrons, patrons themselves, and funding sources to operate the Laboratory. Finally, in terms of new/potential entrants, because regional hospitals, religious organizations, and dietary corporations have the expertise, facilities, and/or financial resources, they have the potential to move into the industry although this is not likely in the short run.

\section{Social Factors}

Among the factors in the external environment, social trends (e.g., changes in lifestyles and attitudes) have the most significant influence on the general public's belief toward "wellness" physically and mentally. For example, the percentage of the U.S. population who favor exercises as a leisure-time activity increased from 2\% in 1995 to $8 \%$ in 2008 (Kotler and Kelly, 2012), which, in turn, resulted in growing fitness programs such as lifestyle elements, nutrition, and health coaching (Nied, 2016). In other words, consumers in general want to purchase products that make them feel good in terms of mind, body, and soul (Bhagat, 2016). Also, 
instead of low price, customer value (i.e., the ratio of what is received to what is given up, or the ratio of benefits to sacrifice) is becoming a much more important in the consumption decision making process. Simply, American consumers, especially Millennial consumers, are now taking route in buying more thoughtfully (Bhagat, 2016). Furthermore, according to Millennials, with wellness becoming a way of life for Americans, a healthy mind is being fueled. Finally, social media, which have become an integral part of daily lives, are making profound changes in the way consumers obtain and search for information.

The US population is growing, living longer, and becoming more ethnically diverse (Cohn, 2016). However, almost 60 percent of the rural counties not adjacent to metropolitan areas experience population declines (Lamb, Hair and McDaniel, 2017). Additionally, because they are aging, especially Baby Boomers (the individuals who were born between 1946 and 1964) are re-allocating and re-directing their energy, time, and funds on their own wellness (e.g., health care and vacation). Finally, there are over 7 million stroke survivors in the US every year (American Stroke Association, 2016).

\section{Political and Legal Trends}

The increase in health care costs, nationally, is steadily on the rise. Many physicians and healthcare providers are working with exercise professionals to provide a "preventative" form of medicine. Furthermore, many companies and organizations are offering employee worksite wellness programs to help employees get "healthy" and reduce insurance, medicine, and physician costs (ACSM Certified News, 2010). Another trend within the health/wellness arena is that privacy laws are now applicable to exercise professionals and facilities. The Health Insurance Portability and Accountability Act of 1996 (HIPAA) and The Family Educational Rights and Privacy Act (FERPA) are two laws that health clubs need to adhere to when working with clients and their information (Relland, 2008).

\section{Economic and Technological Environment}

Although some are still recovering from the scars from the Great Recession (e.g., construction), the overall economy seems to be healthy. For example, average family incomes rose slightly in 2013 and 2014, and the unemployment rate was 5.6 percent in early 2015, the lowest in 6 years (Lamb, Hair and McDaniel, 2017).

Worldwide technological innovations and advancements (e.g., improvement in computers, emergence of social media sites on the prevalently-used Internet, increasingly powerful compact mobile devices, etc.) are occurring at a rapid pace.

Swot Analysis 


\section{LWMB's Strengths}

Instead of positioning itself as a place for rehabilitation, the LWMB stresses the importance of becoming a center of "total well-being". Given the current trend of staying "well and healthy" and the rising medicine and physician costs, the Laboratory creates an image that is appealing to its target market.

The customer value is sustained by the amount of benefits received by patrons and the amount of sacrifice made by patrons (Lamb, Hair and McDaniel, 2017). The benefits, in the form of both core and supplementary services, include personalized/customized services, caring personnel, friendly process, and a comfortable environment. Furthermore, there is no charge to receive the service (i.e., the financial sacrifice does not exit). Taking both of the factors into consideration, the LWMB offers high customer value.

The inquiries of the Laboratory can be done through abundant communication channels and are addressed promptly. The steps needed to use the Laboratory are minimal; the processes of using the Laboratory are simple; and the patrons' needs are attended to promptly with personalization/customization.

The kinesiology professor, the GAs, and the interns are enthusiastic about being part of the LWMB for professional as well as personal reasons. Professionally, the LWMB has been part of the professor's career and of kinesiology students' education for years. Personally, both have the same philosophy of helping and supporting the patrons and their families. Additionally, the positive attitude exhibited by the patrons and their families provides more "reasons" for the professor and the students to continuously to work with them.

Because the building in which the LWMB resides is the main workout and practice facility for the University's athletes, there are lots of amenities (e.g., pool, stairs, etc.) available to facilitate the LWMB's operations. The proximity to other amenities provides substantial savings for the Laboratory.

The LWMB is supported by the University and the University System. However, the main support comes from the Kinesiology Department in the College of Education at the University. Support from the Department, the College, the University, and the University System provide strong motivation for the LWMB to fully develop its potential.

\section{LWMB's Weaknesses}

Due to its lack of segmentation (i.e., the first step of a target market strategy), the LWMB is unable to allocate its already limited resources effectively and efficiently (Lamb, Hair and McDaniel, 2017). At present, because of the small size of the Laboratory's target market, 
segmentation seems to be unnecessary. Nevertheless, after the LWMB starts to grow, segmentation will be a critical first-step in developing its marketing strategy.

The operation hours are convenient for the students (i.e., interns and graduate assistants), but not for the patrons and those who accompany them to the Laboratory.

From marketing communications' stand point, LWMB's efforts have been fragmented, inconsistent, and scarce. Relying heavily and solely on WOM, the LWMB is unable to communicate with its target markets effectively and efficiently. This, in turn, hinders LWMB's ability to create awareness and interest from its target markets to partake in the Laboratory's activities, not to mention actually participating in these activities and to create a unique brand image.

More importantly, due to the complexity of how to describe what the Laboratory is offering and to demonstrate the benefits of using the offerings, it is a struggle for the LWMB to design appropriate appeals and/or messages from the perspective of communication.

With the turnover of interns each semester, it is difficult to build up personal relationships among the patrons, their families, and the interns. This is especially true when all three parties need to work closely for the patrons to achieve "total well-being".

The space is crowded and may not be up to the ADA standards. According to the ADA standards, "at least one of each type of exercise equipment or machine must have clear floor space of at least 30 by 48 inches and be served by an accessible route. If the clear space is enclosed on three sides (e.g., by walls or the equipment itself), the clear space must be at least 36 by 48 inches" (United States Access Board, 2016). In addition to the patrons and the ones who accompany them, there are typically 14 interns in the Laboratory. At times, because there are students who visit the Laboratory as part of their assignments and visitors who admire and are curious about what the Laboratory is about, the crowdedness is even more noticeable.

Outside of the Building, there is a limited amount of handicapped parking spaces available for the patrons in need. Since no appointment is necessary for them to use the Laboratory, the patrons may not be able to use the parking space adjacent to the Building when demand is greater than supply.

\section{Opportunities}

As a combination of social (e.g., increasing U.S. population, increasing number of valueconscious individuals, etc.) and demographic (e.g., increasing number of aging Baby Boomers, and the number of stroke survivors, etc.) trends, the demand for the LWMB's offerings is growing. The growing health care costs and the slow recovery from the economic downturn make the LWMB's offerings even more attractive. 
As far as technological advancement is concerned because the technology itself is becoming more widely available and easily accessible, information that can be obtained by individuals and organizations is more substantial in quantity and higher in quality than before (Schiffman and Wisenblit, 2015). From an organizational perspective, technology provides new alternatives for businesses to operate more effectively and efficiently. From the standpoint of how individuals/families collect information, an important step in the decision-making process, technology improves the quality of their decisions.

\section{Threats}

From the perspective of competition, there is intense competition coming from the substitutes, the potential entrants, the suppliers, and the buyers. In terms of the substitutes, the number of competitors (i.e., a large number of competitors) and the nature of the offerings (i.e., total wellness is abstract in nature) make the competition very forceful. Also, given their expertise and resources, the industry is very appealing to the potential entrants. Furthermore, the bargaining power of suppliers represents another threat. For example, it is the LWMB's "burden" to solicit funds to operate the Laboratory. Finally, there is a considerable number of alternatives for buyers to choose from both in the substitutes and from the potential entrants. All four forces represent a high level of threat to the LWMB.

Due to limited cognitive capability, individuals are selective in filtering through the information, or, to a degree, they simply ignore the marketing communications efforts by different organizations altogether (Schiffman and Wisenblit, 2015).

\section{Recommendations To Improve Lwmb’s Business Model}

\section{Target Market Strategy}

The market of LWMB consists of individuals "who have been released from conventional healthcare and usually have had a stroke or injury that has left them paralyzed" and their families. Because these individuals and families can be very demographically and socioeconomically diverse, demographic segmentation in general is not helpful in identifying the target markets. Instead, geographic segmentation with region or state as a variable can be used as a starting point of segmentation. As a result, the LWMB can start targeting individuals and families who live in the region of Central Texas or the state of Texas. These individuals and families are chosen, because of their geographic proximity to the Laboratory. The proximity to the Laboratory also means that, due to the services provided being facilitydependent, the patrons and their families do not need to travel a long distance to visit the Laboratory. In other words, because the sacrifice, in the form of time and energy spent on traveling, will be kept at a minimum, the Laboratory still provides a high customer value. 


\section{Internal Marketing Strategy}

Given its low awareness level even within the University campus, it is imperative that the Laboratory engage in both internal and external marketing activities. Therefore, the target market of the internal marketing (i.e., marketing activities that treat employees as customers) (Kotler and Keller, 2012) includes both full- and part-time employees who are involved in the University's daily operations. This target market should be the first target market that the LWMB needs to reach for the following reasons. First, changes (e.g., the development and introduction of new products) in any organization typically require buy-ins from employees. For that reason, the new products, or a product that is less known in this case, should be clearly and precisely communicated to the employees internally. Second, once there are buy-ins, employees can serve as opinion leaders to spread the word; this adds another dimension to the WOM heavily used by the LWMB.

\section{Modifications to the Marketing Mix}

Given the marketing strategy recommended, there is no need for the LWMB to expand its offerings. Nevertheless, it is suggested that the LWMB change its brand name. For example, because the term, laboratory, suggests that the LWMB is a place conducive to testing and/or experimentation, the patrons are associated with "subjects". From the interns' and the GAs' perspectives, it seems to be appropriate to use the term, laboratory, given the nature of their responsibilities involved; they are obtaining hands-on experience in a field setting. From the patrons' perspective, they are much more than "subjects" in a laboratory; they are individuals working on their own future.

In addition to "laboratory", the LWMB may consider changing the "motor behavior" to other terms. "Motor behavior" is very straightforward in terms of explaining what the LWMB is about from a technical stand point (i.e., the attributes of the services). It, nevertheless, does not explicitly connote the benefits of LWMB's offerings. Finally, it is recommended that research, especially qualitative research such as focus groups, be conducted before the decisions of whether to change LWMB's name and the extent of change be made.

Even though not charging patrons is considered a strength, it is recommended that the LWMB consider starting charging a small fee (e.g., a registration fee) for the purpose of keeping its operations running smoothly while maintaining its nature as a not-for-profit entity. Because of a growing patron base and limited funding sources, the LWMB needs to be, at least, selfsufficient from the perspective of financial stability. Although the LWMB receives private donations and the university support, and benefits from free labor, the LWMB might be able to offer better services with extra funds.

The current operation hours (Monday through Friday, 8:00 a.m. - 12:00 p.m., and Monday through Thursday, 1:00 p.m. - 3:00 p.m.) are convenient for the interns and GAs. They, 
nevertheless, may not be convenient for the patrons and their families. Therefore, it is recommended that the current operation hours be modified. For example, instead of from 8:00 a.m. to $12: 00$ p.m., the Laboratory may want to change the hours to 9:00 a.m. to 1:00 p.m. so that the patrons and their families can fully utilize their lunch break for the purpose of using the LWMB's offerings. For the afternoon hours, it is recommended that the Laboratory operates from 3:00 p.m. to 6:00 p.m. and five days a week, instead of 4 days a week. To the patrons and their families, the additional one-hour daily renders more flexibility, while the extension to 6:00 p.m. affords more convenience. These recommendations are made from the perspective of patrons and their families, instead of from the interns and GAs. Additionally, the traffic on campus is usually much lighter in the afternoon than in the morning. The implementation of these recommendations will, no doubt, resolve the issue of parking to some degree.

In the long run, the LWMB should consider offering its services during the weekends, especially around noon on Saturdays and in the afternoon on Sundays. After the implementation of the recommended strategy (i.e., market extension), the demand for LWMB's offerings is likely to increase. The extension of operations from weekdays only into weekends is likely to smooth over the unbalanced demand and supply.

It is recommended that the Laboratory have an orientation session for the patrons and their families. The purposes of the orientation are to (1) let the patrons and their families know how to work with the Laboratory, (2) reduce the likelihood of post-consumption cognitive dissonance (i.e., the inner tension that a consumer experiences after recognizing an inconsistency between behavior and values/opinions) from the patrons and their families (Schiffman and Wisenblit, 2015), and (3) give the patrons and their families realistic expectations in terms of the offerings. In addition to the orientations themselves, an informational packet, redesigned from and expanded on the current pamphlet, with similar content should be distributed to the patrons and their families. In doing so, it will reinforce the educational purpose of the orientation. On top of being used in the orientations, the informational packet will need to be made available throughout the gym and in all University campuses/locations.

Along with the above mentioned, the LWMB ought to take an active role in participating in the University sponsored events as part of the College. For example, even though they are designed to acquaint potential students and their parents with the University, Texan Tours, held at least once a semester, provide an additional opportunity to enhance the awareness level of the Laboratory's existence and its purposes. Similarly, Texan Scholars Orientations and Texan Orientations, held multiple times a semester, lend one more opportunity for the Laboratory. Traditionally, there is "Academic College/Departmental Showcase" in the morning of the Orientations. Although it is only about one hour in length, the Showcase does denote an opportunity. 
As far as off-campus events are concerned, the LWMB can piggy-back on the University's recruiting efforts by participating in the annual events held in Arlington and/or Austin areas. The audience showing up in the main campus events will no doubt be different from the one in Arlington/Austin events. The LWMB, nonetheless, will benefit from the difference; after all, both groups of audience are part of the Laboratory's target markets.

A third area that the LWMB can work on is social media. Social media, a channel that has the ability to reach mass audience and the flexibility to personalize/customize the message, is beneficial for the LWMB to use. Given their ability to attract different generations (e.g., Millennials, Generation X, Baby Boomers), the current usage of social media under the Laboratory should be expanded and enhanced. For example, instead of using them as a static information source, social media should be a place for people to have interactions and conversations/dialogues. The content of the "conversations/dialogues" should, therefore, be relevant, interesting, and up-to-date. The purposes of doing so are to keep participants' interest at a high level and to build up relationships with the participants.

It is also recommended that the Laboratory continues using WOM as part of its marketing communications efforts, because, as a personal information source, it is more credible in the service industry and not-for-profit sectors. In order to use WOM effectively, the LWMB needs to start working with the Office of Alumni Association to obtain contact information of alumni who had worked in the Laboratory as interns, and, subsequently, encourage these alumni to play the role of opinion leaders to "spread the word" for it.

Finally, as far as the production of marketing communication materials is concerned, there are three approaches that the LWMB can use: (1) produce all materials by itself through its staff, interns, and GAs (i.e., a DIY approach), (2) involve students and faculty from the Department of Kinesiology/College of Education and the Department of Communication Studies/College of Liberal and Fine Arts (i.e., collaboration), and (3) request professional support from the University's Department of Marketing and Communications and voluntary services from alumni or a professional advertising agency. The materials produced through the DIY and the collaboration approaches will no doubt be more "natural" than those of the professional support approach. At the same time, both of them provide evidence to the target markets in terms of the commitment made by the Departments and the Colleges to advocate LWMB's offerings. Nevertheless, they are not as professional as the ones produced by the third approach. Therefore, it is recommended that the LWMB work with the University's Department of Marketing and Communications, and perhaps request voluntary services from alumni or a professional advertising agency for the production of marketing materials.

With regard to the distribution of the marketing materials, the printed ones should be made available throughout the university gym and in all University campuses/locations, as mentioned earlier. The videos, alternatively, should be used in conjunction with social media, 
webpage, and other channels. For example, the videos can be posted on YouTube. Although the videos may still need to be "discovered" by the target markets and they are still an impersonal communication, YouTube is a readily available, widely acceptable, and highly popular communication channel after all.

Also, for their routine visits to the Laboratory, it is recommended that the LWMB encourage its patrons set up appointments in advance for the following reasons. First, it will help the Laboratory decipher the patterns of supply and demand, and, subsequently, to balance the two. Second, the Laboratory will be able to better allocate its interns and limited space in an efficient and effective way without sacrificing the quality of its offerings. Finally, the appointment records together with other pieces of information of the patrons will give the LWMB a good foundation to set up a "customer" data base, which, then, can be used for relationship building.

The high turnover of interns is unavoidable. However, there are initiatives the LWMB can take to resolve the potential negative outcomes of the high intern turnover. First, new interns need to go through orientation and training before officially starting their internships in the Laboratory. Also, after they finish the orientation and training, the new interns should be assigned a mentor. Ideally, the mentor and the mentee should work as a team with a patron until the mentor leaves the program. The main purpose of this mentoring system is to ensure that the process of going through LWMB's offerings is systematic and consistent. Finally, a $\log$ should be kept jointly by the mentor and the mentee. In the log, there should be information regarding patrons' basic demographics, routine activities/exercises, and progress so that the new intern can shorten the time it takes to know the patrons, as well as provide a smooth transition.

With the recommended operation hours and an appointment system, the LWMB will be able to utilize its current facility to a maximum level. However, with the implementation of the recommended market extension strategy and in the long run, the LWMB needs to expand its current facility or relocate its operations. With a bigger facility together with crowd (i.e., patrons, their families, visitors, and interns) control, the Laboratory will be able to offer a safer and more comfortable environment.

\section{Performance Outcomes Of Lwmb's Business Model:}

\section{A Theoretical Framework}

The suggested business model is expected to facilitate the LWMB's continued success and future expansion. The success of LWMB can be measured using four performance variables which are the degrees of the patron's total well-being, total movement, and independent living and the level of the intern's experiential learning. In this part of the study, a theoretical framework (see Figure 1) that shows relationships between these four performance variables 
which are defined as the outcomes of the interaction between the interns and patron is proposed.

Recent improvements in the medicine/medical industries and progress in the living conditions at a global scale have expanded people's lifespans, and in turn, this creates more demand for medical services (WHO, 2015). On the other hand, individuals with disabilities and senior citizens have very limited and poor choices in terms of their independent living options. The number of studies related to independent living is very limited. Given that the number of individuals with disabilities and senior citizens will double within the next twenty years (Harrington et al., 2002), it is imperative to find ways to make these individuals less dependent on other individuals. Improving their mobility and well-being will help them become more independent. Healthcare professionals recommend people do regular daily activities including, but not limited to, daily exercises, housekeeping, lifting, walking around, climbing stairs, parking far away from the stores, etc. to move more. These activities improve the quality of life for the individual.

Figure 1. Performance Outcomes of LWMB's Business Model

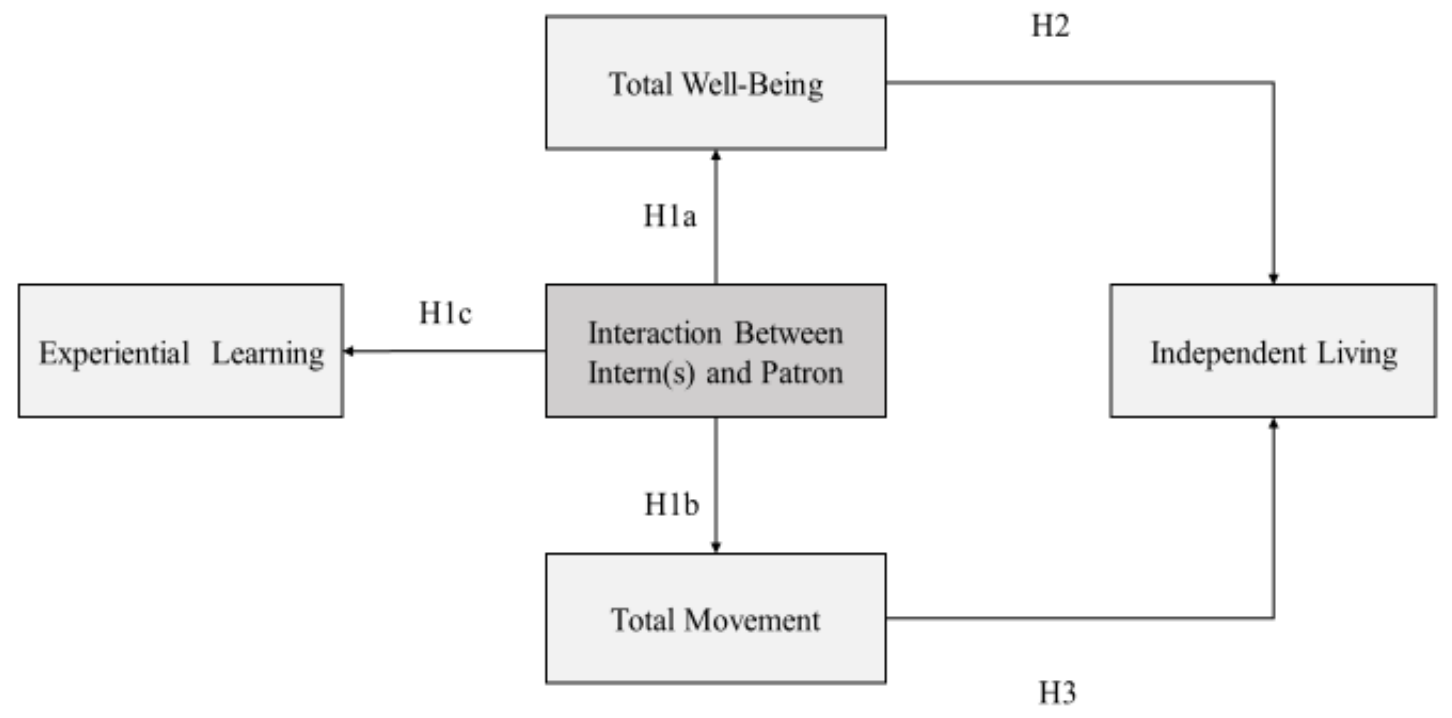

\section{Interaction between the intern(s) and the patron}

The LWMB's new business model improves the interactions between the interns and patrons in four ways: First, the internal marketing strategy that is recommended to the LWMB be adopted will motivate interns to develop better professional relationships with patrons and deliver better care to them. Second, by offering an orientation session for the patrons and their 
families, the LWMB will let the patrons and their families know how to work with the Laboratory, reduce the likelihood of their post-consumption cognitive dissonance and dissatisfaction, and give them realistic expectations in terms of the offerings. All these are likely to improve the interactions between the interns and patrons. Third, with the recommended operation hours and an appointment system, the LWMB will be able to increase the quality and quantity of the interactions between the interns and patrons. Finally, the recommended mentoring system will ensure that the process of utilizing LWMB's offerings is systematic and consistent in spite of the high intern turnover rate. A log kept jointly by the mentor and the mentee regarding patrons' basic demographics, routine activities/exercises, and progress will help the new intern shorten the time it takes to know the patrons and develop better interactions with them.

The LWMB provides services that improve patrons' total movement, total well-being and conditions to live independently. The quality of the intern-patron interaction affects the patron's total movement and total well-being. In the literature, the patient and caregiver relationship has been examined extensively specifically for older patients. It is hard to evaluate this relationship for stroke survivors since there are not many studies on this issue. The literature reveals that "...the physician-patient relationship itself can offer therapeutic care to patients. A physician's attention, warmth, caring, concern, and practical assistance, as well as accurate and open communication, can make a tremendous difference to the health of older patients." (Williams et al., 2007, p. 464). There is strong evidence suggesting that interactions between the medical professional and the patient affect the patient's well-being.

As long as the interactions between medical professionals and patients continue, the patients' well-being improves. If the relationship between the patient and the care provider is lost, the patients' well-being may be affected negatively. It may be concluded that “... rehabilitation programs may effectively increase physical activity levels among participants, but once the programs end, levels decline. It would be helpful for rehabilitation practitioners to refer their discharged patients to relevant community-based physical activity programs, but these programs are not widely available, with the possible exception of those for persons with arthritis" (Rosenberg et al., 2011, p. 9).

The LWMB facilitates the interaction between interns and patrons which creates a positive learning environment for the interns. When they interact with patrons, interns gain hands-on experience related to their area of interest. Experience is considered as one of the main tools in terms of valuable source of knowledge (Benner, 1984). Clinical teaching is the most important component of modern science. "Clinical teaching - that is, teaching and learning focused on, and usually directly involving, patients and their problems - lies at the heart of medical education" (Spencer, 2003, p.591). Based on the arguments and evidence presented above, the following hypotheses can be postulated. 
HIa: The greater the level of interactions between the intern(s) and the patron, the greater the level of the patron's well-being.

H1b: The higher the level of interaction between the intern(s) and the patron, the higher the degree of the patron's total movement.

H1c: The higher the level of interaction between the intern(s) and the patron, the higher the degree of the intern's experiential learning.

\section{Linkage between Total Well-Being and Independent Living}

Although there are some disagreements on a precise definition of well-being, it is widely accepted that well-being is a subjective concept. According to Diener \& Suh (1997), wellbeing consists of three interrelated components which are life satisfaction, pleasant affect, and unpleasant affect. Diener \& Suh (1997) argued that "Affect refers to pleasant and unpleasant moods and emotions, whereas life satisfaction refers to a cognitive sense of satisfaction with life" (p.200). It is also known that an individual's functional independence, disability, morbidity, and mortality are defined by that individual's physical function (Garber et al., 2011). A person's well-being is considered as that person's own perception of his/her overall life circumstances and also reflects that person's perception of level of satisfaction with his/her lifestyle as a whole (Diener, 2000). It is also clear that the well-being of disabled people may contribute to their independent living. The following hypothesis describes the relationship between total well-being and independent living.

H2: The higher the level of the patron's total well-being, the higher the level of the patron's independent living

\section{Linkage between Total Movement and Independent Living}

There are a lot of studies focusing on muscle glycogen and its effect on individual behaviors. Muscle glycogen concentration in trained and untrained subjects significantly differs depending on the subjects' exercise activities (Hickner et al., 1997). It was also shown that aerobic endurance, agility, mobility, flexibility, muscle strength and balance have significant impact on the physical independence of a person (Huang et al., 2010). A study conducted over 65 years and older adults indicated that "weight loss alone or exercise alone improves physical function and ameliorates frailty in obese older adults; however, a combination of weight loss and regular exercise may provide greater improvement in physical function and amelioration of frailty than either intervention alone. Therefore, weight loss combined with regular exercise 
may be beneficial in helping obese older adults maintain their functional independence" (Villareal et al., 2011, p.1227-1228). Functional independence does also improve the person's quality of life which is defined by The World Health Organization as “... a broad ranging concept affected in a complex way by the person's physical health, psychological state, personal beliefs, social relationships and their relationship to salient features of their environment" (World Health Organization, 1997). The following hypothesis can be suggested related to the relationship between total movement and independent living.

H3: The greater the degree of the patron's total movement, the greater the degree of the patron's independent living.

\section{Conclusions}

The main purpose of this study was to analyze the business model of a not-for-profit university laboratory (LWMB) which provides services for stroke survivors and to provide recommendations to improve it. In the final part of the study, a theoretical framework that is based on performance outcomes of the suggested business model was proposed. It was argued that the recommended business model, if implemented by LWMB completely and effectively, will lead to better interactions between the interns and patrons of the Laboratory. According to the results of the literature review, better interactions between the interns and patrons increase the levels of total well-being and total movement of the patrons and facilitate experiential learning of the interns. The ultimate outcome of the recommended business model is to increase the prospect of independent living for the patrons.

The LWMB have several strengths and weaknesses. With the recommended business model, the Laboratory will be able to take full advantage of its strengths (e.g., positioning itself as a center of "total well-being", offering high customer value, providing quality services for patrons, having personnel with high motivation and dedication, having many amenities nearby, and receiving strong administrative support) and overcome its weaknesses (e.g., having inconvenient operation hours for patrons, having an unclear target market strategy, not having an organized marketing communications strategy, and having the high personnel turnover rate) or reduce their adverse effects. The LWMB operates in a business environment that is characterized by high competitive intensity (from indirect competitors), high technological turbulence, and changing social, legal and economic trends. The LWMB's operating environment possesses some threats (intense competition and informational clutter) and opportunities (expanding market size, rising healthcare costs, and technological advances) for the Laboratory.

The suggested business model and theoretical framework that is based on the outcomes of this business model can be applicable to similar labs or research units that work with people with 
disabilities across the U.S. and the world. The recommendations provided in this study can be useful to those service-oriented businesses that work under similar operating conditions.

\section{References}

ACSM Certified News (2010), Certified News, Indianapolis, IN: ACSM Certification \& Registry Board.

American Stroke Association (2016), "Life After Stroke", http://www.strokeassociation.org/STROKEORG/LifeAfterStroke/RegainingIndepen dence/ Regaining-Independence-After-Stroke_UCM_308547_SubHomePage.jsp

Ansoff, H. Igor (1965), Corporate Strategy, New York, NY: McGraw-Hill.

Benner P. (1984) From Novice to Expert. Excellence and Power in Clinical Nursing Practice.

Addison-Wesley Publishing Company, Menlo Park, CA.

Bhagat, Alisha (2016), "A Little Is A Lot: Health and Wellness Trends 2016", http://www.huffingtonpost.com/alisha-bhagat/a-little-is-a-lot-health-and-wellness trends-2016_b_9393638.html

Cohn, D'Vera (2016), "10 demographic trends that are shaping the U.S. and the world", http://www.pewresearch.org/fact-tank/2016/03/31/10-demographic-trends-that-are shaping-the-u-s-and-the-world/

Diener E. (2000), "The science of happiness and proposal for a national index." American Psychologist. 34-43.

Diener, E., \& Suh, E. (1997). Measuring quality of life: Economic, social, and subjective indicators. Social Indicators Research, 40 (1-2), 189-216.

Garber, C. E., B. Blissmer, M. R. Deschenes et al. (2011), "Quantity and quality of exercise for developing and maintaining cardiorespiratory, musculoskeletal, and neuromotor fitness in apparently healthy adults: Guidance for prescribing exercise," Medicine and Science in Sports and Exercise, vol. 43, no. 7, pp. 1334-1359.

Harrington C, LeBlanc AJ, Wood J, Satten NF, Tonner MC. (2002) "Met and unmet need for Medicaid home- and community-based services in the states." Journal of Applied Gerontology. 21(4):484-510.

Hickner, R. C., J. S. Fisher, P. A. Hansen, S. B. Racette, C. M. Mier, M. J. Turner, J. O.

HolloszY (1997), Journal of Applied Physiology, Vol. 83 No. 3, 897-903.

Huang, Wen-Ni Wennie, S. Perera, J. Vanswearingen, and S. Studenski (2010), "Performance measures predict onset of activity of daily living difficulty in 
community-dwelling older adults," Journal of the American Geriatrics Society, vol. 58, no. 5, pp. 844-852, 2010.

Illario M, Vollenbroek-Hutten M, Molloy DW, Menditto E, Iaccarino G, Eklund P. (2015), "Active and Healthy Ageing and Independent Living", Journal of Aging Research.

Kotler, Philip \& Alan R. Andreasen (1996), Strategic Marketing for Non-Profit Organizations, $5^{\text {th }}$ ed., Upper Saddle $\quad$ River, NJ: Pearson Prentice Hall.

Kotler, Philip \& Kevin Lane Keller (2012), Marketing Management, $14^{\text {th }}$ ed., Upper Saddle River, NJ: Pearson Prentice Hall.

Laboratory for Wellness \& Motor Behavior (LWMB) (2016), http://www.tarleton.edu/lwmb/index.html.

Lamb, Charles W., Jr., Joseph F. Hair, Jr., \& Carl McDaniel (2017), Marketing 10, Mason, $\mathrm{OH}$ : South-Western Cengage Learning.

Nied, Jennifer (2016), “16 Wellness Trends for 2016”, http://www.americanspa.com/spablog/16-wellness-trends-2016.

Porter, Michael E. (1980), Competitive Strategy: Techniques for Analyzing Industries and Competitors, New York, NY: Free Press.

Priest, Joe W. (2016), Personal Interview.

Priest, Joe W. (2017), “After Everybody Else Gave Up", Page Publishing Inc, New York, NY.

Relland, S. (2008), "Legal Compliance for Wellness Programs," Employee Benefit Plan Review, p.5-8.

Rosenberg, D. E., Bombardier, C. H., Hoffman, J. M., \& Belza, B. (2011). "Physical Activity Among Persons Aging with Mobility Disabilities: Shaping a Research Agenda." Journal of Aging Research.

Schiffman, L. G. \& Wisenblit, J. (2015), Consumer Behavior, $11^{\text {th }}$ ed., Upper $\quad$ Saddle River, NJ: Pearson Prentice Hall.

Spencer J. (2003) Learning and teaching in the clinical environment. BMJ: British Medical Journal.

Tanner, C. A., Benner, P., Chesla, C. and Gordon, D. R. (1993), The Phenomenology of

Knowing the Patient. Image: The Journal of Nursing Scholarship, 25: 273-280.

United States Access Board (2016), "Exercise Equipment and Machines", https://www.access-board.gov/guidelines-and-standards/recreationfacilities/guides/sports-facilities/exercise-equipment-and-machines

WHO, World Report on Ageing and Health, WHO, Geneva, Switzerland, 2015. 
Williams, S. L., Haskard, K. B., \& DiMatteo, M. R. (2007), The therapeutic effects of the physicianolder patient relationship: Effective communication with vulnerable older patients. Clinical Interventions in Aging, 2(3), 453-467.

Wirtz, Jochen, Patricia Chew, \& Christopher Lovelock (2012), Essentials of Services Marketing, 2nd ed., Upper Saddle River, NJ: Pearson Prentice Hall.

Villareal, Dennis T., Suresh Chode, Nehu Parimi, David R. Sinacore, Tiffany Hilton, Reina Armamento-Villareal, Nicola Napoli, Clifford Qualls, and Krupa Shah (2011), New England Journal of Medicine 2011; 364:1218-1229.

Zeithaml, Valarie A., Mary Jo Bitner, \& Dwayne D. Gremler (2013), Services Marketing, 4th ed., New York, NY: McGraw-Hill/Irwin. 